\title{
Tin Nanoparticles Encapsulated Carbon Nanoboxes as High-Performance Anode for Lithium-Ion Batteries
}

\author{
Ziming Yang ${ }^{1 \dagger}$, Hong-Hui $\mathrm{Wu}^{2+}$, Zhiming Zheng ${ }^{1}$, Yong Cheng ${ }^{1}$, Pei $\mathrm{Li}^{1}$, Qiaobao Zhang ${ }^{1 *}$ \\ and Ming-Sheng Wang ${ }^{1 *}$
}

${ }^{1}$ Department of Materials Science and Engineering, College of Materials and Pen-Tung Sah Institute of Micro-Nano Science and Technology, Xiamen University, Xiamen, China, ${ }^{2}$ Department of Chemistry, University of Nebraska-Lincoln, Lincoln, NE, United States

OPEN ACCESS

Edited by:

Jiexi Wang,

Central South University, China

Reviewed by:

Renzong Hu,

South China University of Technology,

China

Huiqiao Li,

Huazhong University of Science and

Technology, China

Chuanxin $\mathrm{He}$

Shenzhen University, China

*Correspondence:

Qiaobao Zhang

zhangqiaobao@xmu.edu.cn

Ming-Sheng Wang

mswang@xmu.edu.cn

†These authors have contributed equally to this work

Specialty section: This article was submitted to

Nanoscience,

a section of the journal

Frontiers in Chemistry

Received: 21 September 2018 Accepted: 12 October 2018

Published: 31 October 2018

Citation:

Yang Z, Wu H-H, Zheng Z, Cheng Y, Li P, Zhang Q and Wang M-S (2018)

Tin Nanoparticles Encapsulated Carbon Nanoboxes as

High-Performance Anode for

Lithium-lon Batteries.

Front. Chem. 6:533.

doi: 10.3389/fchem.2018.00533
One of the crucial challenges for applying Sn as an anode of lithium-ion batteries (LIBS) is the dramatic volume change during lithiation/delithiation process, which causes a rapid capacity fading and then deteriorated battery performance. To address this issue, herein, we report the design and fabrication of Sn encapsulated carbon nanoboxes (denoted as Sn@C) with yolk@shell architectures. In this design, the carbon shell can facilitate the good transport kinetics whereas the hollow space between Sn and carbon shell can accommodate the volume variation during repeated charge/discharge process. Accordingly, this composite electrode exhibits a high reversible capacity of $675 \mathrm{mAh} \mathrm{g}^{-1}$ at a current density of $0.8 \mathrm{~A} \mathrm{~g}^{-1}$ after 500 cycles and preserves as high as $366 \mathrm{mAh} \mathrm{g}^{-1}$ at a higher current density of $3 \mathrm{~A} \mathrm{~g} \mathrm{~g}^{-1}$ even after 930 cycles. The enhanced electrochemical performance can be ascribed to the crystal size reduction of $\mathrm{Sn}$ cores and the formation of polymeric gel-like layer outside the electrode surface after long-term cycles, resulting in improved capacity and enhanced rate performance.

Keywords: lithium-ion battery, anode material, yolk-shell structure, Sn@C nanoboxes, electrochemical performance

\section{INTRODUCTION}

Over the past few decades, rechargeable secondary lithium-ion batteries (LIBs) have become one of the most popular energy sources for electric vehicles, various portable devices, and grid-scale storage systems because of their high capacity, terrific safety, and steady cycling performance (Bruce et al., 2012; Mahmood et al., 2016; Li et al., 2017b; Liu et al., 2018). However, with the increasing demand of longer usage time and higher capacity about the batteries, graphite, as the widely used commercial anode materials, gradually cannot meet the market needs for its relatively low theoretical capacity of $372 \mathrm{mAh} \mathrm{g}^{-1}$ (Hu et al., 2012a; Lim et al., 2012; Leng et al., 2016; Zhang et al., 2018b). Therefore, extensive researches of alloy-based materials ( $\mathrm{Si}, \mathrm{Ge}, \mathrm{Sn}$, etc.) have been studied in LIBs for the higher capacity of these anode materials (Obrovac and Chevrier, 2014; Li et al., 2017a; Wang et al., 2017, 2018; Zhang et al., 2018a). Metallic Sn was reported with high theoretical capacity $\left(997 \mathrm{mAh} \mathrm{g}^{-1}\right.$ ), good electroconductibility and non-toxicity (Hassoun et al., 2007; Hu et al., 2008, 2011, 2012b). However, the giant volume change of 260\% during lithiation/delithiation process would result in the pulverization of the active materials after long cycles, and thus the fast capacity fading (Rhodes et al., 2012). 
To solve these problems, reducing the size of Sn particles seems to be a good solution because the nano-particles could endure higher stress and effectively prevent the active materials from pulverization (Leng et al., 2015). Nevertheless, nanoparticles prefer to aggregate during the charge and discharge process. A promising strategy to mitigate this drawback is the smart hybridization of $\mathrm{Sn}$ with carbon-based materials (graphene, carbon nanotube, etc.) to Sn@carbon composites (Zhang et al., 2014; Huang et al., 2015; Cheng et al., 2016; Qin et al., 2016), wherein the carbon materials could significantly prevent aggregation, buffer the stress concentration resulted from volume expansion and enhance the electroconductibility. Among them, the yolk@shell structure of Sn@C composites is a preferable choice because the hollow space between the core and carbon shell could accommodate more volume variation free from breaking the carbon shell, which could improve the performance of active materials compared with the Sn@C core@shell composites (Zhang et al., 2014, 2017; Qin et al., 2016).

Inspired by the previous work, herein, we synthesize Sn@C nanoboxes with yolk-shell nanostructure comprising a spherelike Sn core within a hollow cavity surrounded by carbon nanobox via a one-pot spray pyrolysis process followed by hydrogen-thermal reduction. By virtue of structural advantages, the as-prepared electrode exhibits an outstanding reversible capacity of $675 \mathrm{mAh} \mathrm{g}^{-1}$ at a current density of $0.8 \mathrm{~A} \mathrm{~g}^{-1}$ after 500 cycles. The crystal size reduction of $\mathrm{Sn}$ cores and the formation of polymeric gel-like layer outside the electrode surface during cycling could explain the increase of the reversible capacity during long cycles. The current work shed light on the improvement of anode materials for next-generation highperformance LIBs.

\section{EXPERIMENTAL}

\section{Synthesis of $\mathrm{ZnSnO}_{3}$ Nanocubes}

The $\mathrm{ZnSnO}_{3}$ nanocubes are fabricated via a hydrothermal precipitation method according to the literature (Zhang et al., 2017). In a typical process, $2.875 \mathrm{~g}(10 \mathrm{mmol})$ of zinc sulfate heptahydrate $\left(\mathrm{ZnSnO}_{4} \cdot 7 \mathrm{H}_{2} \mathrm{O}\right)$ is added into $100 \mathrm{~mL}$ deionized water and stirred till completely dissolved, and then $20 \mathrm{~mL}$ of sodium stannate solution $\left(\mathrm{NaSnO}_{3} \cdot 3 \mathrm{H}_{2} \mathrm{O}, 2.667 \mathrm{~g}, 10 \mathrm{mmol}\right)$ is added into above zinc sulfate heptahydrate solution. The solution turns into milky immediately and the mixed solution is stirred at $70^{\circ} \mathrm{C}$ for $4 \mathrm{~h}$. After the reaction, the precipitates are collected by centrifugation and washed with deionized water and alcohol 3 times and dried at $60^{\circ} \mathrm{C}$ for one night.

\section{Synthesis of Sn@C Nanoboxes}

According to the literature (Zhang et al., 2017), $0.5 \mathrm{~g} \mathrm{ZnSnO}_{3}$ nanoparticles, 0.46 cetyltrimethylammonium bromide, and $14.08 \mathrm{~mL} \mathrm{H}_{2} \mathrm{O}$ are added into a beaker before $0.5 \mathrm{~h}$ ultrasonic treatment and $1 \mathrm{~h}$ stirring, then $0.7 \mathrm{~g}$ resorcinol, $56.0 \mathrm{~mL}$ absolute ethanol and $0.2 \mathrm{~mL} \mathrm{NH}_{3} \cdot \mathrm{H}_{2} \mathrm{O}$ are added successively and stirred for $0.5 \mathrm{~h}$ at $35^{\circ} \mathrm{C}$. Finally, $0.1 \mathrm{~mL}$ formaldehyde is added by dropwise. After $6 \mathrm{~h}$ stirring and polymerization by aging over one night, the obtained $\mathrm{ZnSnO}_{3} @$ resorcinol formaldehyde (RF) nanoboxes are collected by centrifugation and washed with deionized water and alcohol 3 times respectively. The yolk-shell $\mathrm{Sn} @ \mathrm{C}$ powder is obtained by heated the $\mathrm{ZnSnO}_{3} @ \mathrm{RF}$ at $600^{\circ} \mathrm{C}$ for $5 \mathrm{~h}$ with a rate of $2^{\circ} \mathrm{C} \min ^{-1}$ under $\mathrm{H}_{2}$ (5\%)/ $\mathrm{Ar}(95 \%)$ atmosphere.

\section{Synthesis of Sn NPs}

$1.0 \mathrm{~g} \mathrm{ZnSnO}_{3}$ nanoparticles are heated at $600^{\circ} \mathrm{C}$ for $5 \mathrm{~h}$ with a rate of $2^{\circ} \mathrm{C} \min ^{-1}$ under $\mathrm{H}_{2}(5 \%) / \operatorname{Ar}(95 \%)$ atmosphere.

\section{Characterizations}

The crystal structure is recorded by a powder X-raying diffraction (Ri gaku Ultima IV). The structure and morphology of the samples are investigated via an FEI Talos-F200s transmission electron microscope (TEM) and a Zeiss SUPRA 55 scanning electron microscope (SEM). Thermogravimetric analysis is investigated by an SDT Q600 Simultaneous TGA/DSC

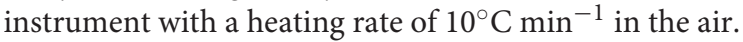

\section{Electrochemical Measurements}

The electrochemical measurements are carried out by employing CR2025 coin cells and the working electrode is synthesized via mixing the active materials, conductive acetylene black and sodium carboxymethylcellulose with a weight ratio of $8: 1: 1$. The slurry is coated on a $\mathrm{Cu}$ foil and dried at $80^{\circ} \mathrm{C}$ inside a vacuum oven for $12 \mathrm{~h}$. The $\mathrm{Cu}$ foil is first cut into circular disks with a diameter of $14 \mathrm{~mm}$, and the masses of the asobtained $\mathrm{Cu}$ foil circular disk $\left(\mathrm{m}_{1}\right)$ and the slurry coated on the $\mathrm{Cu}$ foil circular disk after dried $\left(\mathrm{m}_{2}\right)$ are determined using a microbalance (Mettler Toledo XS3DU) with an accuracy of $1 \mu \mathrm{g}$. The active mass of mass loading of the electrode is then calculated as $0.8^{*}\left(\mathrm{~m}_{2}-\mathrm{m}_{1}\right)$ and about $0.8 \mathrm{mg} \mathrm{cm}^{-2}$. The measured specific capacities of the electrodes are based on the total active mass loading of Sn@C. Li foil is taken as a counter electrode and 1 M $\mathrm{LiPF}_{6}$ is mixed with ethyl carbonate, dimethyl carbonate, and diethyl carbonate $(\mathrm{EC} / \mathrm{DMC} / \mathrm{DC}=1: 1: 1$, volume ratio) are used as the electrolyte. The cells are assembled in the Ar-glovebox under Ar atmosphere with both oxygen and moisture below $0.1 \mathrm{ppm}$. Galvanostatic charge-discharge cycles are tested in the CT2001A LAND battery tester with potential windows of $0.01-$ $3.00 \mathrm{~V}$. And cycle voltammetry measurements are conducted via a CHI660E electrochemical workstation under a scanning rate of $0.1 \mathrm{mV} \mathrm{s}^{-1}$. Electrochemical impedance spectroscopy (EIS) is measured in the frequency range from 0.01 to $100 \mathrm{kHz}$ at open circuit potential with an amplitude of $5 \mathrm{mV}$.

\section{RESULTS AND DISCUSSION}

As illustrated in Figure 1, the resorcinol-formaldehyde (RF) is coated outside of the cubic $\mathrm{ZnSnO}_{3}$ nanoboxes, and then the $\mathrm{ZnSnO}_{3} @ \mathrm{RF}$ is heated at $600^{\circ} \mathrm{C}$ under the $\mathrm{H}_{2}(5 \%) / \mathrm{Ar}$ atmosphere for $300 \mathrm{~min}$ (Zhang et al., 2017). During this process, resorcinol formaldehyde is gradually turned into an amorphous carbon shell while $\mathrm{SnO}_{2}$ and $\mathrm{ZnO}$ are reduced to metallic Sn and $\mathrm{Zn}$. Due to the low boiling point $\left(907^{\circ} \mathrm{C}\right), \mathrm{Zn}$ gradually evaporates from the material, which finally generates the yolkshell Sn@C composite (Zhang et al., 2014). Compared with other reported methods (Zhang et al., 2008; Ni et al., 2013; Wang et al., 
2013a, 2015), this one-pot spray pyrolysis method could product yolk-shell Sn@C composite more efficient and controllable.

The X-ray diffraction patterns of the $\mathrm{ZnSnO}_{3}$ and $\mathrm{Sn} @ \mathrm{C}$ are shown in Figure 2A. Most peaks of the precursor could be allocated to the $\mathrm{ZnSnO}_{3}$ phase (JCPDS NO: 11-0274). After hydrogen-thermal reduction, the final product shows sharp peaks which are indexed to the Sn Phase (JCPDS No: 04-0673). Obviously, there are no obvious diffraction peaks from $\mathrm{Zn}, \mathrm{SnO}_{2}$, or $\mathrm{ZnO}$, which suggests that most $\mathrm{Zn}$ and $\mathrm{O}$ had been removed from the precursor. The thermogravimetric curve of the material after hydrogen-thermal reduction (Figure 2B) shows that the loss of weight below $200^{\circ} \mathrm{C}$ is ascribed to the evaporation the residual moisture. In addition, the distinct loss from 450 to $560^{\circ} \mathrm{C}$ is attributed to the carbon oxidization whereas the increase from 200 to $450^{\circ} \mathrm{C}$ is caused by the gradual oxidization of $\mathrm{Sn}$ to $\mathrm{SnO}_{2}$. The slight increase after $450^{\circ} \mathrm{C}$ may be attributed the further oxidization of some inner $\mathrm{Sn}$ that is not oxidized completely. Assuming the final materials is $\mathrm{SnO}_{2}$, the carbon content of the Sn@C nanoboxes is about $21 \%$ from the following equation:

$$
\begin{aligned}
\mathrm{Sn}(\mathrm{wt} \%) & =100 \times \frac{\text { molecular weight of } \mathrm{Sn}}{\text { molecular weight of } \mathrm{SnO} 2} \\
& \times \frac{\text { final weight of } \mathrm{SnO} 2}{\text { initial weight of } \mathrm{Sn} @ \mathrm{C}}
\end{aligned}
$$

Scanning electron microscope (SEM) and TEM are employed to observe the morphology and structure of the active materials. As presented in Figures 3a,b, the size of cubic $\mathrm{ZnSnO}_{3}$ ranges from 180 to $200 \mathrm{~nm}$. The element mapping and energy dispersive spectrometer of $\mathrm{ZnSnO}_{3}$ are shown in Figures S3, S4, respectively. The cubic $\mathrm{ZnSnO}_{3} @ \mathrm{RF}$ is fabricated successfully by coating the RF with a uniform thickness of $\sim 20 \mathrm{~nm}$ (Figure 3c). After hydrogen-thermal reduction treatment, the outside RF transforms into amorphous carbon while the inside $\mathrm{ZnSnO}_{3}$ gradually decomposed, leading to a majority of $\mathrm{Zn}$ volatilize from the carbon shell for the relatively low boiling point $\left(907^{\circ} \mathrm{C}\right)$. However, $\mathrm{Sn}$ is conserved because of the relatively high boiling point $\left(2,260^{\circ} \mathrm{C}\right)$. The remaining $\mathrm{Sn}$ transforms into the spherical structure to form the yolk-shell Sn@C structure when it is cooled to room temperature. According to Figures 3d,e,g, the TEM and SEM images clearly show the yolk-shell structure where the material in core position is $\mathrm{Sn}$ nanoparticles $(\sim 100 \mathrm{~nm})$ and the outside shell is carbon $(\sim 30 \mathrm{~nm})$. The well-designed yolk-shell structure could completely contain the Sn nanoparticles in each carbon shell and prevent the aggregation of nanoparticles. The selected-area electron diffraction (SAED) patterns shown in the inset of Figure 3d demonstrate the highly crystalline of Sn cores and amorphous nature of carbon shell. A small amount of Sn outflows from the carbon shell, which may be caused by the ultrasmall holes in the carbon shell. As shown in Figure 3f, the highresolution TEM image displays a series of parallel fringes with a space around $0.295 \mathrm{~nm}$, which can be indexed to the (200) plane of crystalline Sn (JCPDS no. 04-0673). Furthermore, the STEM

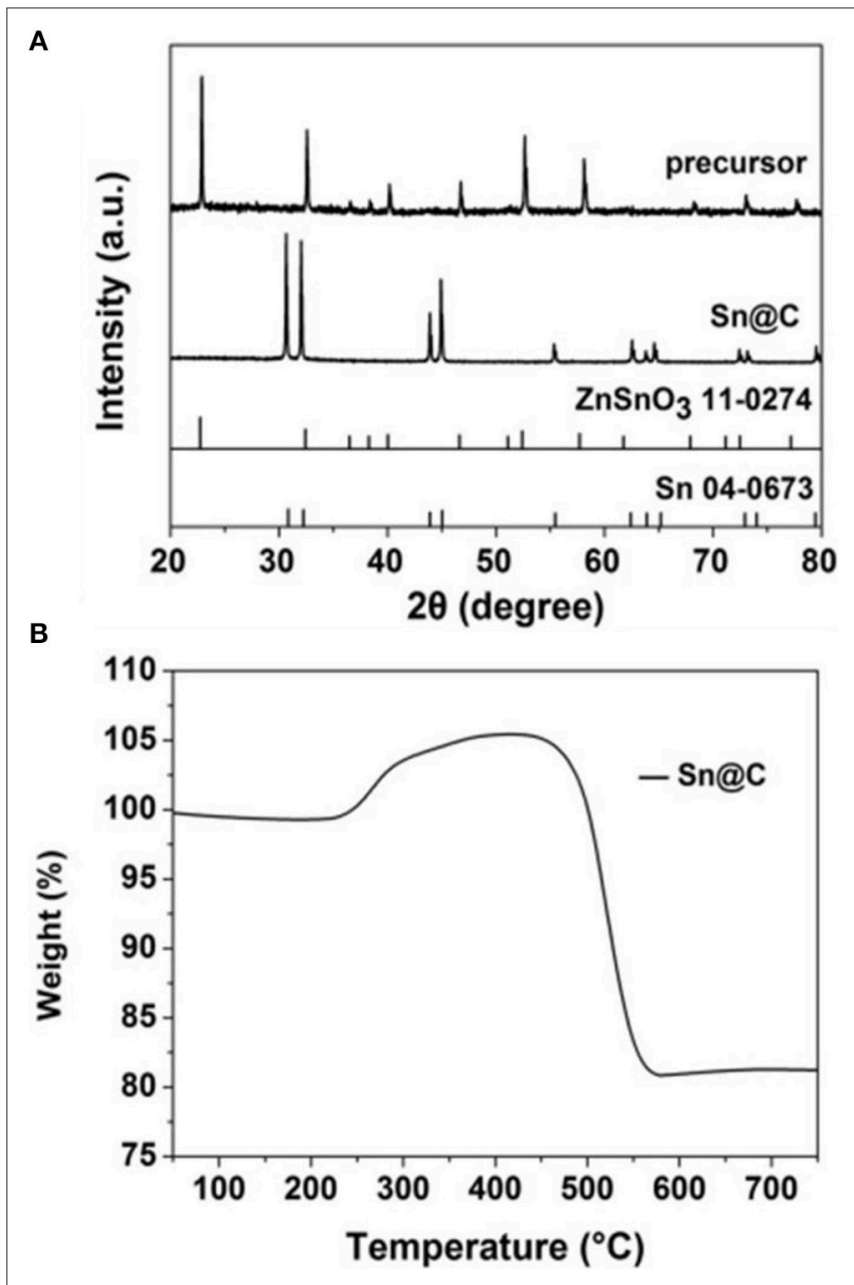

FIGURE 2 | (A) XRD pattern of precursor and Sn@C, (B) TGA profile of Sn@C.
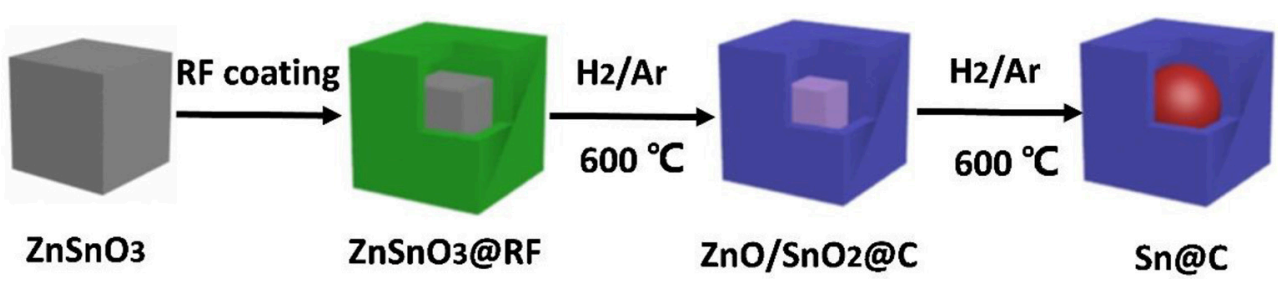

FIGURE 1 | Schematic diagram of the fabrication procedure of yolk-shell Sn@C nanobox. 


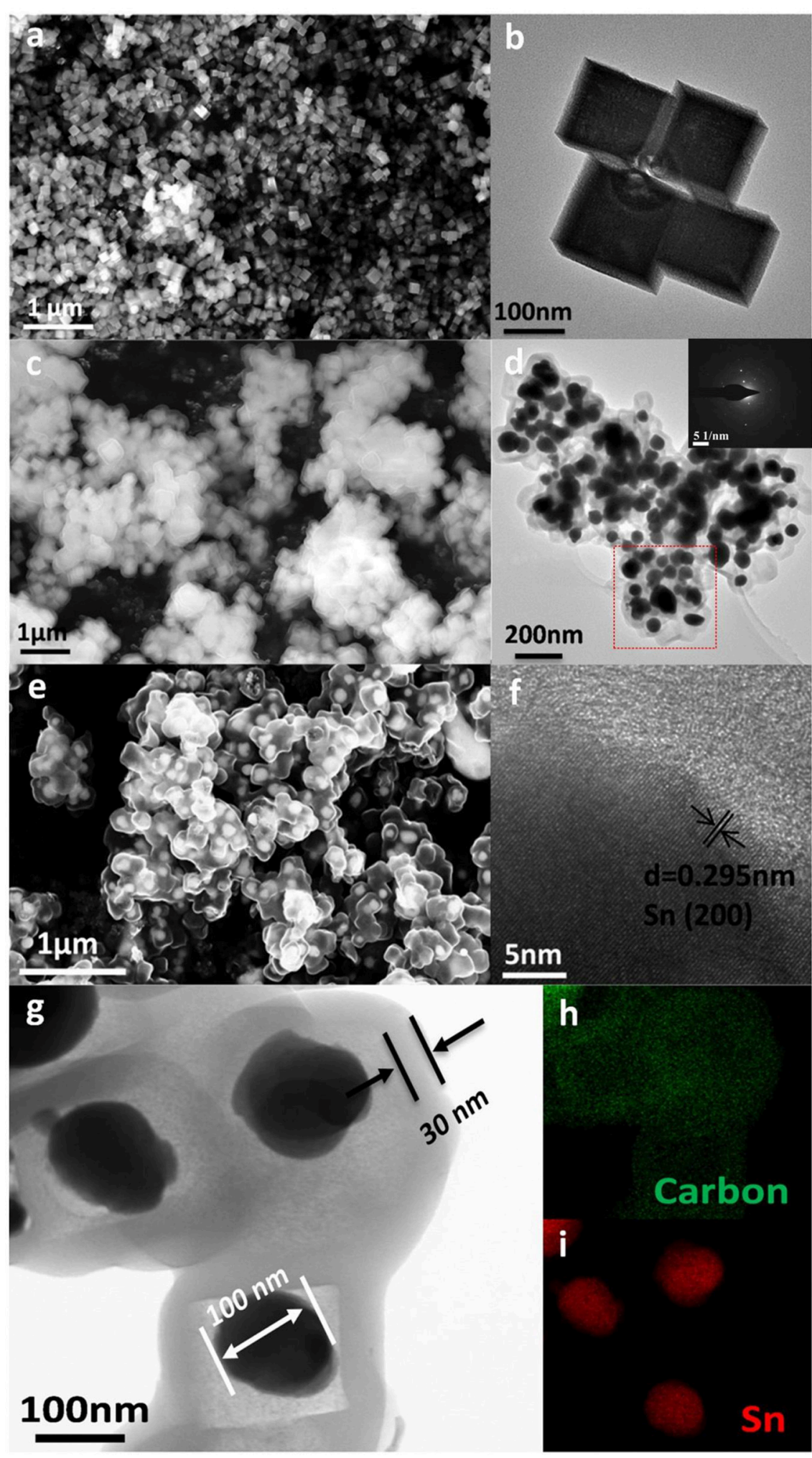

FIGURE 3 | (a) SEM, (b) TEM image of cubic $\mathrm{ZnSnO}_{3}$, (c) SEM of $\mathrm{ZnSnO}_{3} @ \mathrm{RF}$, (d) TEM, inset is its corresponding SAED patterns taken from the rectangular area, (e) SEM, and (f) high-resolution TEM image of Sn@C, (g) its corresponding STEM image, (h,i) corresponding elemental mapping of (h) Carbon and (i) Sn, respectively. 
image (Figure 3g) and element mapping image in Figures $\mathbf{3 h}, \mathbf{i}$ shows that the Sn nanoparticles locate in the carbon shell without any $\mathrm{Zn}$ signal, which suggests that most $\mathrm{Zn}$ is removed from the shell during the thermal treatment. Besides, the void space in the yolk-shell structure is about $60 \%$, which is designed to accommodate the volume variation during the $\mathrm{Li}^{+}$insertion/deinsertion reaction. As a comparison, the XRD and SEM images of Sn NPs are shown in Figures S1, S2.

Cyclic voltammograms of the Sn@C electrode (Figure 4A) are tested to understand the electrochemical reactions during the charge/discharge processes. As can be seen, during the first cathodic scan, the three small peaks at $0.25,0.5$, and $0.55 \mathrm{~V}$ can be attributed to the alloying reaction between lithium and tin, forming of $\mathrm{Li}_{\mathrm{X}} \mathrm{Sn}$ alloys (Dai et al., 2016). During the first anodic scan, four oxidation peaks between 0.40 and $0.80 \mathrm{~V}$ are assigned to the delithiation process of $\mathrm{Li}_{\mathrm{X}} \mathrm{Sn}$ alloys ( $\mathrm{Li}$ et al., 2013; Liu J. et al., 2015). Besides, the broad peak at $1.25 \mathrm{~V}$ is caused by the $\mathrm{Li}^{+}$extraction from carbon. In addition, there is a peak at $2.85 \mathrm{~V}$ in the first anodic scan, which disappears in the following cycles, and may be due to solid electrolyte interface (SEI) layer decomposition induced by nanoscaled Sn particles (Dai et al., 2016). The difference between the first and following cycles are caused by the electrolyte decomposition and formation of SEI films (Luo et al., 2012; Xu et al., 2012; Liu Y. et al., 2015). Figure 4B exhibits the charge and discharge profiles of the yolk-shell Sn@C nanoboxes at a current density of $0.8 \mathrm{~A} \mathrm{~g}^{-1}$ over a voltage range from 0.01 and 3.0 V. Compared with the first cycle of charge curve, the plateau at $0.48 \mathrm{~V}$ of the following cycles gradually disappears, besides, the charge and discharge curves become sloping, indicating a linear timedependent change of potential at a constant current. Combined with the CV curves, the slope curves could be caused by the diffusion-controlled reaction and the capacitive capacity. The disappearance of potential plateaus in the following cycles and the linearization of the charge-discharge curve indicate the extra pseudocapacitive contribution (Augustyn et al., 2013; Li et al., 2015; Xu et al., 2016). The charge and discharge profiles of the Sn NPs at $0.8 \mathrm{~A} \mathrm{~g}^{-1}$ over a voltage between 0.01 and $3.0 \mathrm{~V}$ are given in Figure S5. To further explore the electrochemical properties of the active materials, long cycling test (Figure 4C) is carried out. The Sn@C yolk-shell materials deliver initial discharge and charge capacities of 821.5 and $500.3 \mathrm{mAh} \mathrm{g}^{-1}$ at
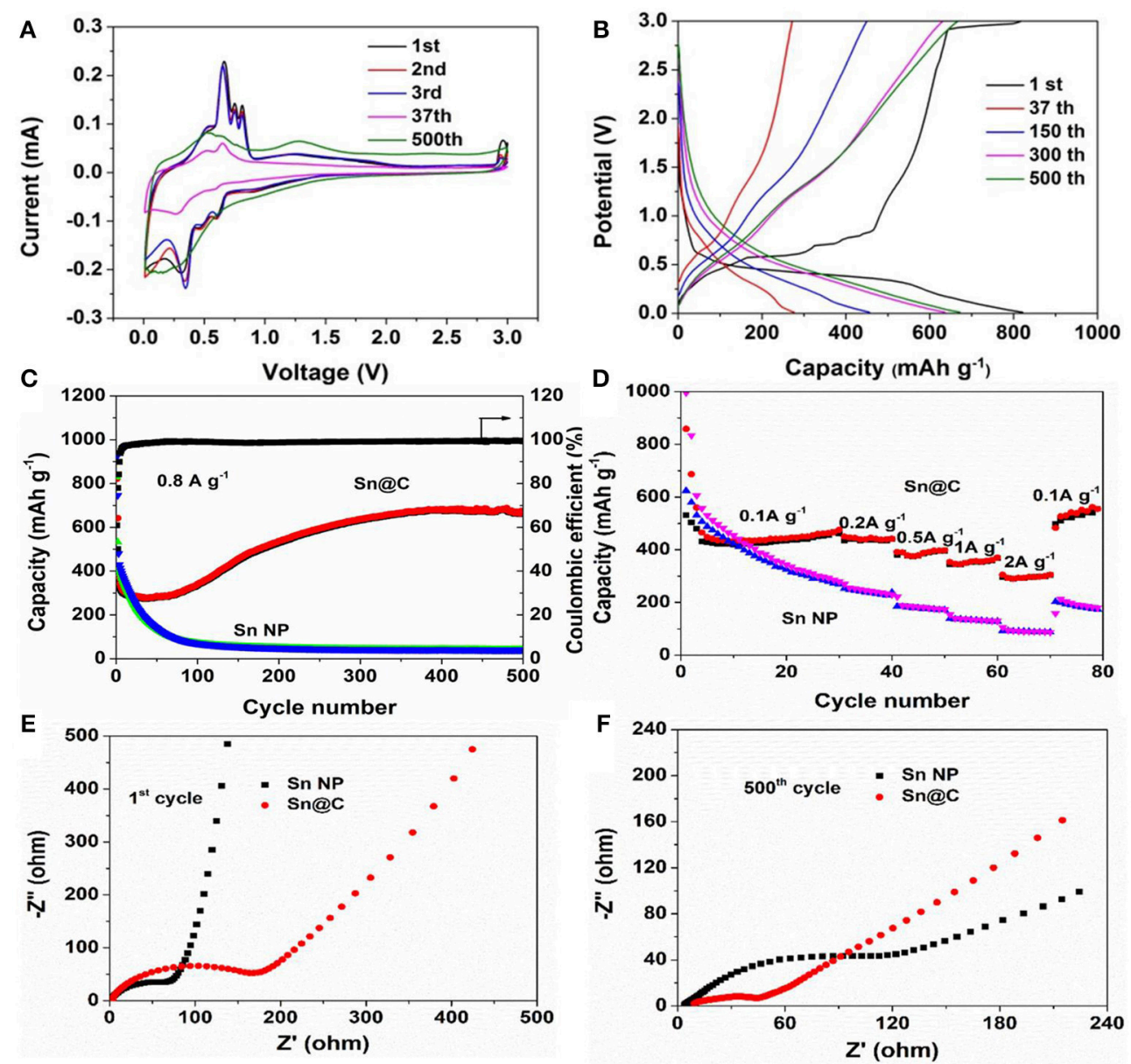

FIGURE 4 | (A) CV curves of Sn@C at a scanning rate of $0.1 \mathrm{mV} \mathrm{s}^{-1}$ between 0.1 and $3 \mathrm{~V}$, (B) charge-discharge curves of Sn@C at $0.8 \mathrm{~A} \mathrm{~g} \mathrm{~g}^{-1}$, (c) cycling performance of Sn@C and Sn NPs at 0.8 $\mathrm{A} \mathrm{g}^{-1}$, (D) rate capacity of Sn@C and Sn NPs, (E) Nyquist plots of samples before cycle, (F) Nyquist plots of samples after 500 cycles. 
$0.8 \mathrm{~A} \mathrm{~g}^{-1}$ in a voltage range from 0.01 to $3 \mathrm{~V}$, corresponding to the first coulombic efficiency of $60.9 \%$ (Figure 4C). The largely irreversible capacity loss at the first cycle is related to the formation of SEIs consuming active $\mathrm{Li}$, and can be compensated by prelithiation through either chemical or electrochemical methods or by using stabilized Li metal powder (Zhang et al., 2018a; Zheng et al., 2018a). The reversible capacity quickly decreases to $272.3 \mathrm{mAh} \mathrm{g}^{-1}$ at 37 th cycle, which could mainly be attributed to the structural degradation and reorganization (Sun et al., 2014). Interestingly, the coulombic efficiency gradually increases to $98.5 \%$ from the 2 nd cycle to 37 th cycle, indicating that a relatively stable SEI layer forms during the initial cycles and renders the active surface substantially inert to further electrolyte decomposition, despite the extreme volume changes experienced by the underlying material during discharge/charge (Zhang et al., 2018a). The capacity after 37th cycle gradually increases to $674.6 \mathrm{mAh} \mathrm{g}^{-1}$ after 500 cycles, suggesting an excellent cycling performance. Such an improved performance is mainly due to the following features: the Sn@C yolk-shell structure could steadily encapsulate the Sn nanoparticles and the hollow space between the carbon shells and the Sn cores could effectively buffer expansion caused by the giant volume expansion. Such an increased capacity has also been observed in the other $\mathrm{Sn} / \mathrm{C}$ composites, $\mathrm{SnO}_{2} / \mathrm{C}$ composites and other metal oxide composites (Wang et al., 2010, 2012, 2013b; Guo et al., 2013; Xu et al., 2013; Liu Y. et al., 2015). It is general for various metal (Cheng et al., 2016) or metal oxides (Sun et al., 2013; Sn, Wang et al., 2013b, Mn, Yu et al., 2006; Liu et al., 2014; Xiao and Cao, 2015; Lian et al., 2017, Co, Laruelle et al., 2002, Fe, Zheng et al., 2018b) electrodes to exhibit such a capacity rise. Recent studies show that the capacity rise may be caused by the reversible formation and decomposition of an organic polymeric/gel-like layer from the electrolyte decomposition. And the polymeric/gel layer outside the active materials could enhance the mechanical cohesion and provide extra $\mathrm{Li}^{+}$insertion sites at the interface of the active materials, which is called "pseudo-capacitance-type behavior" (Wang et al., 2012). Moreover, the gradually increased intensity of the peaks at about $0.6 \mathrm{~V}$ (Figure 4B) may be due to the reversible decomposition of the organic polymeric/gellike layer. It has been confirmed that the layer forms at low voltage and decomposed at high voltage. On the contrary, the Sn NPs shows an initial reversible discharge capacity of $923.3 \mathrm{mAh}$ $\mathrm{g}^{-1}$ under the same conditions and then the capacity gradually decreases to $71.4 \mathrm{mAh} \mathrm{g}^{-1}$ after 100 cycles. Besides, the cycling performance of Sn@C and Sn NPs at $0.2 \mathrm{~A} \mathrm{~g}^{-1}$ are presented in Figures S6, S7. Figure 4D demonstrates the rate performance of the Sn@C composite. The reversible capacities at the current density of $0.1,0.2,0.5,1$, and $2 \mathrm{~A} \mathrm{~g}^{-1}$ are 499.5, 465.8, 420.0, 389.8 , and $320.3 \mathrm{mAh} \mathrm{g}^{-1}$, respectively, which are much higher than those of the Sn NPs electrode. Besides, when the current density is recovered to $0.1 \mathrm{~A} \mathrm{~g}^{-1}$, a capacity of $509.0 \mathrm{mAh} \mathrm{g}^{-1}$ is obtained and continued to increase after high-rate cycles, indicating that the yolk-shell structure could keep the integrity of the Sn nanoparticles and enable them to work normally at different current density. Figures $4 \mathrm{E}, \mathrm{F}$ displays the impedance spectra of the Sn@C and Sn NPs, respectively. The semicircle in the high frequency is caused by the electrolyte resistance and charge transfer resistance (Liu et al., 2011). Obviously, the semicircle of Sn@C is much bigger than that of Sn NPs at 1st cycle, suggesting that the amorphous carbon shell hinders the $\mathrm{Li}^{+}$ transform at first. In the following cycles, the semicircle of Sn@C gradually decreases but that of the Sn NPs increases, and the semicircle of Sn@C is much smaller than that of Sn NPs at 500th cycle, which indicates that the yolk-shell structure could protect the active materials and decrease the impedance in long-term cycles.

To further understand the underlying mechanism of the reversible capacity increase for yolk-shell Sn@C composites, TEM and SEM are conducted to capture the Sn@C structure after long cycles at $0.8 \mathrm{~A} \mathrm{~g}^{-1}$. The structure and morphology of Sn@C electrodes after 40 and 500 cycles are observed. As shown in Figures 5a,b, after 40 cycles, most $\mathrm{Sn}$ cores swell, which is attributed to the volume change after $\mathrm{Li}^{+}$insertion and extraction process. Additionally, the void space between the carbon shell and Sn core decreases obviously. However, the carbon shell is the same as the pristine state and the Sn nanoparticles are still encapsulated within the shell. Nevertheless, the morphology change is relatively obvious after 500 cycles. According to Figures $\mathbf{5 c}, \mathbf{d}$, most of the $\mathrm{Sn}$ cores transform into smaller nanoparticles with the diameter range $5-10 \mathrm{~nm}$ or even smaller, which is due to the gradually accumulated press/strain caused during the lithiation/delithiation process. Actually, those ultra-small Sn nanoparticles tend to accumulate to a bigger one because the ultra-small nanoparticles have extremely high specific surface area and high surface energy, which could reverse the transform process and cause the rapid capacity decay (Qin et al., 2016). As shown in Figure 5d, a polymericgel-like layer is also formed outside of the Sn@C composite. Such a structure coating outside the Sn@C yolkshell anode could enhance the mechanical cohesion and offer more lithium interfacial storage sites, which is called "pseudocapacitance-type behavior" (Purbia and Paria, 2015; Cheng et al., 2016). Moreover, the carbon shell is able to lock the nanoparticle in each carbon nanobox, and the rearrangement of $\mathrm{Sn}$ nanoparticles could reduce the stress and strain of the electrode and thus reserve the integrated yolk-shell structure (Xu et al., 2012; Leenheer et al., 2016). Such a phenomenon is observed in $\mathrm{MnO}$ (Leenheer et al., 2016), which also exhibits the reversible capacity increase of $800 \mathrm{mAh} \mathrm{g}^{-1}$ at $5 \mathrm{~A} \mathrm{~g}^{-1}$ from 200 to 2,000 cycles. Cao etc. explained that more active materials in carbon sheets may crush into small size nanograins upon cycling, which could increase the specific surface to some extent, thus leading to the enhancement of the interfacial $\mathrm{Li}^{+}$ storage ability and the improved capacity (Yu et al., 2006; Sun et al., 2013; Liu et al., 2014; Xiao and Cao, 2015; Lian et al., 2017).

To investigate the improved chemical performance after long cycles, the rate performance, and cycling properties at high current density are measured. As shown in Figure 6A, after 500 cycles at $0.8 \mathrm{~A} \mathrm{~g}^{-1}$, rate performance of $\mathrm{Sn} @ \mathrm{C}$ is tested at $0.2,0.5$, 1.0, 2.0, and 4.0 $\mathrm{A} \mathrm{g}^{-1}$ and the capacities are 1036.9, 956.0, 839.2, $701.8,395.8 \mathrm{mAh} \mathrm{g}^{-1}$ respectively, which are almost more twice than the capacities of the pristine electrode. From the CV curve (Figure 4A), the electrode also shows relatively smooth curves 


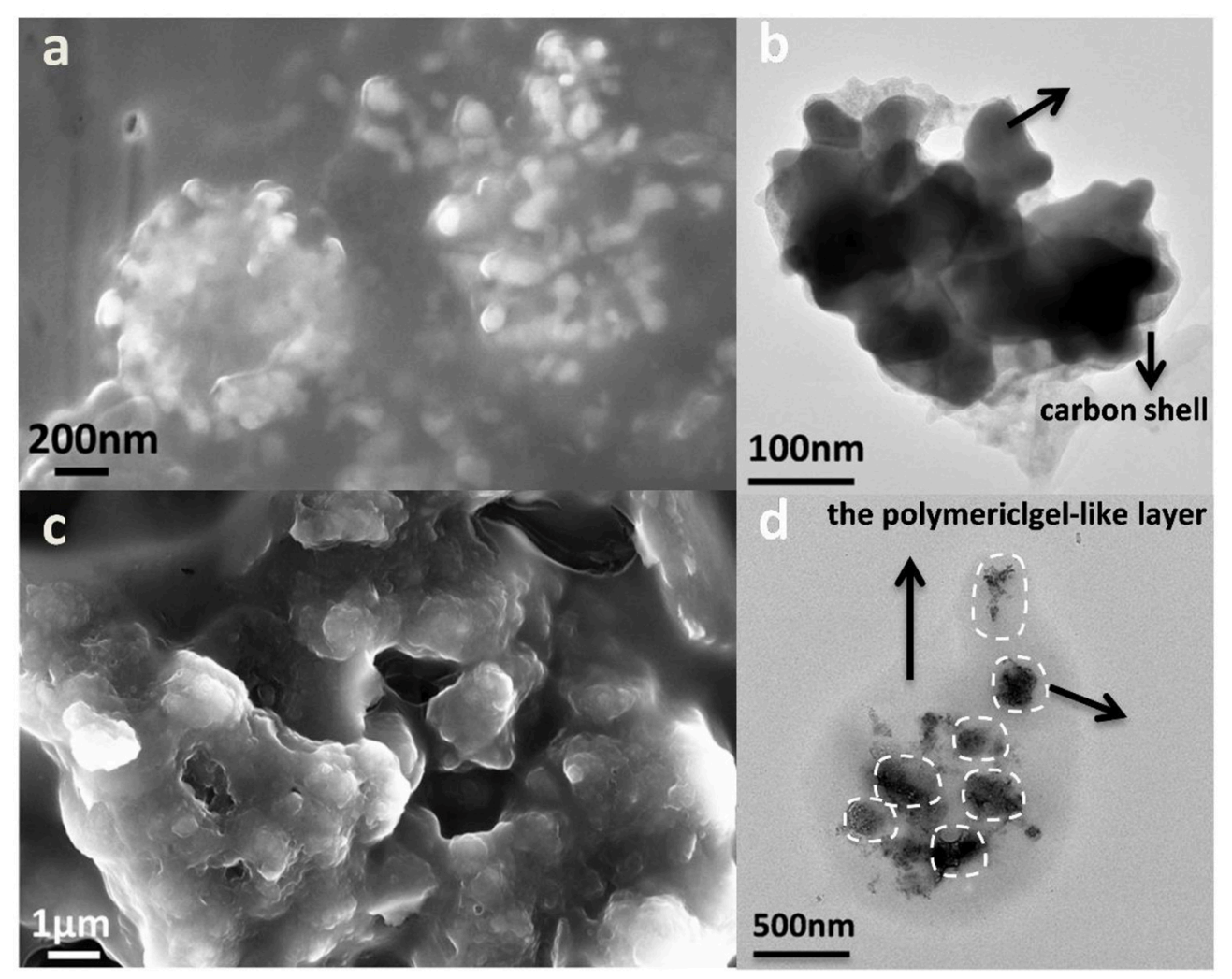

FIGURE 5 | (a) SEM and (b) TEM of Sn@C after 40 cycles at $0.8 \mathrm{~A} \mathrm{~g}^{-1}$, (c) SEM, and (d) TEM of Sn@C after 500 cycles at $0.8 \mathrm{~A} \mathrm{~g}^{-1}$.
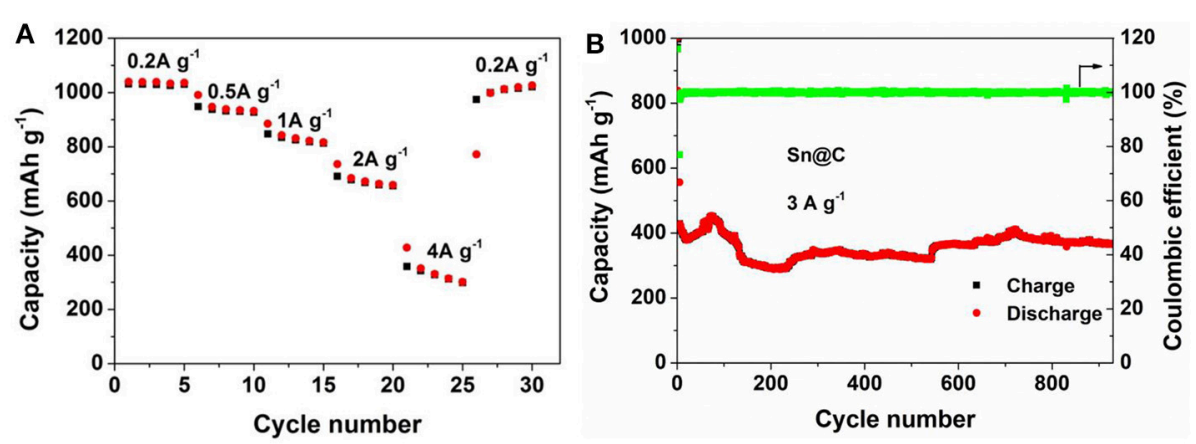

FIGURE 6 | (A) Rate capacity and (B) cycling performance of Sn@C at $3 \mathrm{~A} \mathrm{~g}^{-1}$ after 500 cycles at $0.8 \mathrm{~A} \mathrm{~g}^{-1}$.

of charge and discharge after long cycles, which is caused by the combination of capacitive contribution and diffusion-controlled reaction. According to the charge-discharge curves (Figure 4B), the potential plateaus becomes shorter and almost disappears and the curve becomes nearly straight line after long cycles, explaining the increase of the extra pseudocapacity (Purbia and Paria, 2015). Besides, the electrode is also tested at $3 \mathrm{~A} \mathrm{~g}^{-1}$ after 500 cycles at $0.8 \mathrm{~A} \mathrm{~g}^{-1}$, the reversible capacity (Figure 6B) maintains $366.2 \mathrm{mAh} \mathrm{g}^{-1}$ after 930 cycles and the coulombic efficient is almost $100 \%$. Compared to previous reports, this yolk-shell Sn@C composite exhibits improved reversible capacity of $694.4 \mathrm{mAh} \mathrm{g}^{-1}$ between 16th to 500th cycles at a current density of $0.2 \mathrm{~A} \mathrm{~g}^{-1}$, which have been not observed before (The electrochemical performances of other $\mathrm{Sn} / \mathrm{C}$ composites are shown in the Table S1). Besides, at a current density of $0.8 \mathrm{~A} \mathrm{~g}^{-1}$, the obvious increase between 37 th to 500th cycles approach 402.1 $\mathrm{mAh} \mathrm{g}^{-1}$. Compared with the Sn NPs without carbon shell, the electrochemical performance of Sn@C is considerably improved. Moreover, this concept can also be employed to other anode materials.

The excellent electrochemical performance is contributed by the following aspects: firstly, the uniform Sn nanoparticles are 
completely encapsulated in the amorphous carbon shell, which prevents the aggregation of the nanoparticles, and the hollow space between $\mathrm{Sn}$ core and carbon shell could significantly accommodate the volume variation to protect the carbon shell from pulverization; secondly, the process of forming ultra-small Sn nanoparticles during lithiation/delithiation to maintain the yolk-shell structure; thirdly, the ultra-small Sn nanoparticles of $10-20 \mathrm{~nm}$ after long-term cycles have a larger specific surface area which could provide more $\mathrm{Li}^{+}$insertion location; finally, the polymeric gel-like layer may provide the extrinsic pseudocapacitance after long-term cycles. In conclusion, the transformation of morphology and structure of the yolkshell Sn@C nanoboxes is mainly responsible for the gradual rise of the reversible capacity and the long-term cycling ability.

\section{CONCLUSION}

In summary, we report a facile method to synthesize novel Sn@C nanoboxes into yolk-shell structure with enhanced reversible capacity. The as-prepared Sn@C nanoboxes electrode exhibit good electrochemical performance that can respectively deliver a reversible capacity of $674.6 \mathrm{mAh} \mathrm{g}^{-1}$ at $0.8 \mathrm{~A} \mathrm{~g}^{-1}$ and $1032.2 \mathrm{mAh} \mathrm{g}^{-1}$ at $0.2 \mathrm{~A} \mathrm{~g}^{-1}$ after 500 cycles. There are two main reasons for this distinguished performance: firstly, the $\mathrm{Sn}$ nanoparticles are encapsulated completely in the carbon shell and the void space can significantly accommodate the volume expansion. Besides, the SEI film forms outside the carbon

\section{REFERENCES}

Augustyn, V., Come, J., Lowe, M. A., Kim, J. W., Taberna, P.-L., Tolbert, S. H., et al. (2013). High-rate electrochemical energy storage through $\mathrm{Li}+$ intercalation pseudocapacitance. Nat. Mater. 12, 518-522. doi: 10.1038/nmat3601

Bruce, P. G., Freunberger, S. A., Hardwick, L. J., and Tarascon, J.-M. (2012). $\mathrm{Li}-\mathrm{O}_{2}$ and $\mathrm{Li}-\mathrm{S}$ batteries with high energy storage. Nat. Mater. 11, 19-29. doi: $10.1038 / \mathrm{nmat} 3191$

Cheng, F., Li, W.-C., Zhu, J.-N., Zhang, W.-P., and Lu, A.-H. (2016). Designed synthesis of nitrogen-rich carbon wrapped Sn nanoparticles hybrid anode via in-situ growth of crystalline ZIF-8 on a binary metal oxide. Nano Energy 19, 486-494. doi: 10.1016/j.nanoen.2015.10.033

Dai, R., Sun, W., and Wang, Y. (2016). Ultrasmall tin nanodots embedded in nitrogen-doped mesoporous carbon: metal-organic-framework derivation and electrochemical application as highly stable anode for lithium ion batteries. Electrochim. Acta 217, 123-131. doi: 10.1016/j.electacta.2016.08.051

Guo, J., Yang, Z., and Archer, L. A. (2013). Aerosol assisted synthesis of hierarchical tin-carbon composites and their application as lithium battery anode materials. J. Mater. Chem. A 1, 8710-8715. doi: 10.1039/c3ta11802a

Hassoun, J., Reale, P., and Panero, S. (2007). The role of the interface of tin electrodes in lithium cells: an impedance study. J. Power Sour. 174, 321-327. doi: 10.1016/j.jpowsour.2007.09.046

Hu, R., Liu, H., Zeng, M., Liu, J., and Zhu, M. (2012a). Microsized Sn supported by NiTi alloy as a high-performance film anode for Li-ion batteries. J. Mater. Chem. 22, 9539-9545. doi: 10.1039/C2JM30335C

Hu, R., Liu, H., Zeng, M., Wang, H., and Zhu, M. (2011). Core/shell and multi-scale structures enhance the anode performance of a $\mathrm{Sn}-\mathrm{C}-\mathrm{Ni}$ composite thin film in a lithium ion battery. J. Mater. Chem. 21, 4629-4635. doi: 10.1039/c0jm04173d

Hu, R., Zhang, Y., and Zhu, M. (2008). Microstructure and electrochemical properties of electron-beam deposited $\mathrm{Sn}-\mathrm{Cu}$ thin film anodes for thin film lithium ion batteries. Electrochim. Acta 53, 3377-3385. doi: 10.1016/j.electacta.2007.11.064 shell could maintain steadily during charge/discharge processes. Secondly, the ultra-small Sn nanoparticles gradually crush from the original Sn particles, which can effectively relieve the stress concentration on the electrode during the long cycles. Overall, the proposed concept in this work could be applied to prepare other metal/carbon composites with desired performance in next-generation LIBs electrode materials.

\section{AUTHOR CONTRIBUTIONS}

QZ and M-SW designed this project. ZY carried out the material preparation and electrochemical test; ZY, ZZ, YC, and PL carried out and analyzed the XRD, SEM, and TEM analysis; ZY and $\mathrm{H}$ HW wrote the paper. All authors discussed the results and revised the manuscript.

\section{ACKNOWLEDGMENTS}

This work is financially supported by the Fundamental Research Funds for the Central Universities (Xiamen University: 20720170042) and the National Natural Science Foundation of China (Grants No. 21703185).

\section{SUPPLEMENTARY MATERIAL}

The Supplementary Material for this article can be found online at: https://www.frontiersin.org/articles/10.3389/fchem. 2018.00533/full\#supplementary-material

Hu, R., Zhu, M., Wang, H., Liu, J., Liuzhang, O., and Zou, J. (2012b). Sn buffered by shape memory effect of NiTi alloys as high-performance anodes for lithium ion batteries. Acta Mater. 60, 4695-4703. doi: 10.1016/j.actamat.2012. 05.015

Huang, X., Cui, S., Chang, J., Hallac, P. B., Fell, C. R., Luo, Y., et al. (2015). A hierarchical Tin/Carbon composite as an anode for lithium-ion batteries with a long cycle life. Angew. Chem. Int. Ed. 54, 1490-1493. doi: 10.1002/anie.201409530

Laruelle, S., Grugeon, S., Poizot, P., Dolle, M., Dupont, L., and Tarascon, J. (2002). On the origin of the extra electrochemical capacity displayed by $\mathrm{MO} / \mathrm{Li}$ cells at low potential. J. Electrochem. Soc. 149, A627-A634. doi: 10.1149/1.1467947

Leenheer, A. J., Jungjohann, K. L., Zavadil, K. R., and Harris, C. T. (2016). Phase boundary propagation in Li-alloying battery electrodes revealed by liquid-cell transmission electron microscopy. ACS Nano 10, 5670-5678. doi: 10.1021/acsnano.6b02200

Leng, X., Ding, X., Hu, J., Wei, S., Jiang, Z., Lian, J., et al. (2016). In situ prepared reduced graphene oxide/CoO nanowires mutually-supporting porous structure with enhanced lithium storage performance. Electrochim. Acta 190, 276-284. doi: 10.1016/j.electacta.2015.12.190

Leng, X., Wei, S., Jiang, Z., Lian, J., Wang, G., and Jiang, Q. (2015). Carbonencapsulated $\mathrm{Co}_{3} \mathrm{O}_{4}$ nanoparticles as anode materials with super lithium storage performance. Sci. Rep. 5:16629. doi: 10.1038/srep16629

Li, K., Li, B., Wu, J., Kang, F., Kim, J.-K., and Zhang, T.-Y. (2017a). Ultrafast-charging and long-life li-ion battery anodes of $\mathrm{TiO}_{2}-\mathrm{B}$ and anatase dual-phase nanowires. ACS Appl. Mater. Interfaces 9, 35917-35926. doi: 10.1021/acsami.7b11652

Li, K., Zhou, X., Nie, A., Sun, S., He, Y.-B., Ren, W., et al. (2017b). Discovering a first-order phase transition in the $\mathrm{li}-\mathrm{CeO}_{2}$ system. Nano Lett. 17, 1282-1288. doi: 10.1021/acs.nanolett.6b05126

Li, S., Qiu, J., Lai, C., Ling, M., Zhao, H., and Zhang, S. (2015). Surface capacitive contributions: Towards high rate anode materials for sodium ion batteries. Nano Energy 12, 224-230. doi: 10.1016/j.nanoen.2014.12.032 
Li, W., Yang, R., Zheng, J., and Li, X. (2013). Tandem plasma reactions for Sn/C composites with tunable structure and high reversible lithium storage capacity. Nano Energy 2, 1314-1321. doi: 10.1016/j.nanoen.2013.06.012

Lian, Q., Zhou, G., Liu, J., Wu, C., Wei, W., Chen, L., et al. (2017). Extrinsic pseudocapacitve Li-ion storage of $\mathrm{SnS}$ anode via lithiationinduced structural optimization on cycling. J. Power Sour. 366, 1-8. doi: 10.1016/j.jpowsour.2017.09.009

Lim, A.-H., Shim, H.-W., Seo, S.-D., Lee, G.-H., Park, K.-S., and Kim, D.-W. (2012). Biomineralized Sn-based multiphasic nanostructures for Li-ion battery electrodes. Nanoscale 4, 4694-4701. doi: 10.1039/c2nr31056b

Liu, B., Hu, X., Xu, H., Luo, W., Sun, Y., and Huang, Y. (2014). Encapsulation of $\mathrm{MnO}$ nanocrystals in electrospun carbon nanofibers as highperformance anode materials for lithium-ion batteries. Sci. Rep. 4:4229. doi: 10.1038/srep04229

Liu, H., Wang, G., Liu, J., Qiao, S., and Ahn, H. (2011). Highly ordered mesoporous $\mathrm{NiO}$ anode material for lithium ion batteries with an excellent electrochemical performance. J. Mater. Chem. 21, 3046-3052. doi: 10.1039/c0jm03132a

Liu, J., Kopold, P., Wu, C., Van Aken, P. A., Maier, J., and Yu, Y. (2015). Uniform yolk-shell $\mathrm{Sn}_{4} \mathrm{P}_{3} @ \mathrm{C}$ nanospheres as high-capacity and cycle-stable anode materials for sodium-ion batteries. Energy Environ. Sci. 8, 3531-3538. doi: 10.1039/C5EE02074C

Liu, Y., Liu, D., Wu, H.-H., Fan, X., Dou, A., Zhang, Q., et al. (2018). Improved cycling stability of Na-doped cathode materials Li1.2Ni0.2Mn0.6O2 via a facile synthesis. ACS Sustain. Chem. Eng. 6, 13045-13055. doi: 10.1021/acssuschemeng.8b02552

Liu, Y., Zhang, N., Jiao, L., and Chen, J. (2015). Tin nanodots encapsulated in porous nitrogen-doped carbon nanofibers as a free-standing anode for advanced sodium-ion batteries. Adv. Mater. 27, 6702-6707. doi: 10.1002/adma.201503015

Luo, B., Wang, B., Li, X., Jia, Y., Liang, M., and Zhi, L. (2012). Grapheneconfined Sn nanosheets with enhanced lithium storage capability. Adv. Mater. 24, 3538-3543. doi: 10.1002/adma.201201173

Mahmood, N., Tang, T., and Hou, Y. (2016). Nanostructured anode materials for lithium ion batteries: progress, challenge and perspective. Adv. Energy Mater. 6:1600374. doi: 10.1002/aenm.201600374

Ni, W., Wang, Y., and Xu, R. (2013). Formation of Sn@ C yolk-shell nanospheres and core-sheath nanowires for highly reversible lithium storage. Part. Part. Syst. Character. 30, 873-880. doi: 10.1002/ppsc.201300138

Obrovac, M. N., and Chevrier, V. (2014). Alloy negative electrodes for Li-ion batteries. Chem. Rev. 114, 11444-11502. doi: 10.1021/cr500207g

Purbia, R., and Paria, S. (2015). Yolk/shell nanoparticles: classifications, synthesis, properties, and applications. Nanoscale 7, 19789-19873. doi: 10.1039/C5NR04729C

Qin, J., Liu, B., and Cao, M. (2016). Basil seed inspired design for a monodisperse core-shell sn@C hybrid confined in a carbon matrix for enhanced lithium-storage performance. Chem. Asian J. 11, 3520-3527. doi: 10.1002/asia.201601180

Rhodes, K. J., Meisner, R., Kirkham, M., Dudney, N., and Daniel, C. (2012). In situ $\mathrm{XRD}$ of thin film tin electrodes for lithium ion batteries. J. Electrochem. Soc. 159, A294-A299. doi: 10.1149/2.077203jes

Sun, H., Xin, G., Hu, T., Yu, M., Shao, D., Sun, X., et al. (2014). High-rate lithiationinduced reactivation of mesoporous hollow spheres for long-lived lithium-ion batteries. Nat. Commun. 5:4526. doi: 10.1038/ncomms5526

Sun, Y., Hu, X., Luo, W., Xia, F., and Huang, Y. (2013). Reconstruction of conformal nanoscale $\mathrm{MnO}$ on graphene as a high-capacity and long-life anode material for lithium ion batteries. Adv. Funct. Mater. 23, 2436-2444. doi: 10.1002/adfm.201202623

Wang, D., Li, X., Yang, J., Wang, J., Geng, D., Li, R., et al. (2013a). Hierarchical nanostructured core-shell Sn@C nanoparticles embedded in graphene nanosheets: spectroscopic view and their application in lithium ion batteries. Phys. Chem. Chem. Phys. 15, 3535-3542. doi: 10.1039/C3CP4 $4172 \mathrm{E}$

Wang, D., Yang, J., Li, X., Geng, D., Li, R., Cai, M., et al. (2013b). Layer by layer assembly of sandwiched graphene/ $\mathrm{SnO}_{2}$ nanorod/carbon nanostructures with ultrahigh lithium ion storage properties. Energy Environ. Sci. 6, 2900-2906. doi: 10.1039/C3EE40829A

Wang, G., Leng, X., Han, S., Shao, Y., Wei, S., Liu, Y., et al. (2017). How to improve the stability and rate performance of lithium-ion batteries with transition metal oxide anodes. J. Mater. Res. 32, 16-36. doi: 10.1557/jmr.2016.330
Wang, H., Yang, X., Wu, Q., Zhang, Q., Chen, H., Jing, H., et al. (2018). Encapsulating silica/antimony into porous electrospun carbon nanofibers with robust structure stability for high-efficiency lithium storage. ACS Nano 12, 3406-3416. doi: 10.1021/acsnano.7b09092

Wang, Y.-X., Yang, J., Chou, S.-L., Liu, H. K., Zhang, W.-X., Zhao, D., et al. (2015). Uniform yolk-shell iron sulfide-carbon nanospheres for superior sodium-iron sulfide batteries. Nat. Commun. 6:8689. doi: 10.1038/ncomms9689

Wang, Z., Chen, J. S., Zhu, T., Madhavi, S., and Lou, X. W. (2010). One-pot synthesis of uniform carbon-coated $\mathrm{MoO}_{2}$ nanospheres for high-rate reversible lithium storage. Chem. Commun. 46, 6906-6908. doi: 10.1039/c0cc01174f

Wang, Z., Luan, D., Madhavi, S., Hu, Y., and Lou, X. W. D. (2012). Assembling carbon-coated $\alpha-\mathrm{Fe}_{2} \mathrm{O}_{3}$ hollow nanohorns on the CNT backbone for superior lithium storage capability. Energy Environ. Sci. 5, 5252-5256. doi: 10.1039/C1EE02831F

Xiao, Y., and Cao, M. (2015). Carbon-anchored MnO nanosheets as an anode for high-rate and long-life lithium-ion batteries. ACS Appl. Mater. Interfaces 7, 12840-12849. doi: 10.1021/acsami.5b02171

Xu, D., Chen, C., Xie, J., Zhang, B., Miao, L., Cai, J., et al. (2016). A hierarchical N/S-codoped carbon anode fabricated facilely from cellulose/polyaniline microspheres for high-performance sodium-ion batteries. Adv. Energy Mater. 6:1501929. doi: 10.1002/aenm.201501929

Xu, Y., Guo, J., and Wang, C. (2012). Sponge-like porous carbon/tin composite anode materials for lithium ion batteries. J. Mater. Chem. 22, 9562-9567. doi: 10.1039/c2jm30448a

Xu, Y., Liu, Q., Zhu, Y., Liu, Y., Langrock, A., Zachariah, M. R., et al. (2013). Uniform nano-Sn/C composite anodes for lithium ion batteries. Nano Lett. 13, 470-474. doi: 10.1021/nl303823k

Yu, Y., Shi, Y., and Chen, C. H. (2006). Effect of lithia and substrate on the electrochemical performance of a lithia/cobalt oxide composite thin-film anode. Chem. Asian J. 1, 826-831. doi: 10.1002/asia.200600157

Zhang, N., Zhao, Q., Han, X., Yang, J., and Chen, J. (2014). Pitaya-like Sn@ $\mathrm{C}$ nanocomposites as high-rate and long-life anode for lithium-ion batteries. Nanoscale 6, 2827-2832. doi: 10.1039/C3NR05523J

Zhang, Q., Chen, H., Luo, L., Zhao, B., Luo, H., Han, X., et al. (2018a). Harnessing the concurrent reaction dynamics in active $\mathrm{Si}$ and Ge to achieve high performance lithium-ion batteries. Energy Environ. Sci. 11, 669-681. doi: 10.1039/C8EE00239H

Zhang, Q., Liu, Z., Zhao, B., Cheng, Y., Zhang, L., Wu, H.-H., et al. (2018b). Design and understanding of dendritic mixed-metal hydroxide nanosheets@ $\mathrm{N}$-doped carbon nanotube array electrode for high-performance asymmetric supercapacitors. Energy Stor. Mater. doi: 10.1016/j.ensm.2018.06.026. [Epub ahead of print].

Zhang, S., Zhao, K., Zhu, T., and Li, J. (2017). Electrochemomechanical degradation of high-capacity battery electrode materials. Prog. Mater. Sci. 89, 479-521. doi: 10.1016/j.pmatsci.2017.04.014

Zhang, W. M., Hu, J. S., Guo, Y. G., Zheng, S. F., Zhong, L. S., Song, W. G., et al. (2008). Tin-nanoparticles encapsulated in elastic hollow carbon spheres for high-performance anode material in lithium-Ion batteries. Adv. Mater. 20, 1160-1165. doi: 10.1002/adma.200701364

Zheng, Z., Wu, H.-H., Chen, H., Cheng, Y., Zhang, Q., Xie, Q., et al. (2018a). Fabrication and understanding of $\mathrm{Cu}_{3} \mathrm{Si}-\mathrm{Si} @$ Carbon@ graphene nanocomposites as high-performance anode for lithium-ion batteries. Nanoscale. doi: 10.1039/C8NR07207H. [Epub ahead of print].

Zheng, Z., Zao, Y., Zhang, Q., Cheng, Y., Chen, H., Zhang, K., et al. (2018b). Robust erythrocyte-like $\mathrm{Fe}_{2} \mathrm{O}_{3} @$ carbon with yolk-shell structures as highperformance anode for lithium ion batteries. Chem. Eng. J. 347, 563-573.

Conflict of Interest Statement: The authors declare that the research was conducted in the absence of any commercial or financial relationships that could be construed as a potential conflict of interest.

Copyright (c) 2018 Yang, Wu, Zheng, Cheng, Li, Zhang and Wang. This is an openaccess article distributed under the terms of the Creative Commons Attribution License (CC BY). The use, distribution or reproduction in other forums is permitted, provided the original author(s) and the copyright owner(s) are credited and that the original publication in this journal is cited, in accordance with accepted academic practice. No use, distribution or reproduction is permitted which does not comply with these terms. 